\title{
Standard and Increased-Dose BEACOPP Chemotherapy Compared with COPP-ABVD for Advanced Hodgkin's Disease
}

\author{
Volker Diehl, M.D., Jeremy Franklin, Ph.D., Michael Pfreundschuh, M.D., \\ Bernd Lathan, M.D., Ursula Paulus, Ph.D., Dirk Hasenclever, Ph.D., \\ Hans Tesch, M.D., Richard Herrmann, M.D., Bernd Dörken, M.D., \\ Hans-Konrad Müller-Hermelink, M.D., Eckhardt Dühmke, M.D., \\ and Markus Loeffler, M.D., Ph.D., for the German Hodgkin's \\ Lymphoma Study Group
}

ABSTRACT

From the First Department of Internal Medicine, University of Cologne, Cologne, Germany (V.D., J.F., M.P., B.L., U.P., H.T.); the Institute for Medical Informatics, Statistics and Epidemiology, University of Leipzig, Leipzig, Germany (D.H., M.L.) the Canton Hospital, Basel, Switzerland (R.H.); Charité Hospital, Berlin, Germany (B.D.); the Institute of Pathology, University of Würzburg, Würzburg, Germany (H.-K.M.-H.); and the Department of Radiotherapy, University of Munich, Munich, Germany (E.D.). Address reprint requests to Dr. Diehl at the Klinik I für Innere Medizin, Universität Köln, Joseph-Stelzmann-Str. 9, 50924 Cologne, Germany, or atv.diehl@uni-koeln.de.

N Engl J Med 2003;348:2386-95. Copyright (c) 2003 Massachusetts Medical Society.
BACKGROUND

Faced with unsatisfactory results of treatment for advanced Hodgkin's disease, we investigated three combinations of chemotherapy.

\section{METHODS}

From 1993 to 1998, 1201 eligible patients 15 to 65 years of age who had newly diagnosed Hodgkin's disease in unfavorable stage IIB or IIIA or stage IIIB or IV were randomly assigned to receive eight cycles of cyclophosphamide, vincristine, procarbazine, and prednisone alternating with doxorubicin, bleomycin, vinblastine, and dacarbazine (COPP-ABVD); bleomycin, etoposide, doxorubicin, cyclophosphamide, vincristine, procarbazine, and prednisone (BEACOPP); or increased-dose BEACOPP, each followed by local radiotherapy when indicated. Enrollment in the COPP-ABVD group was stopped in 1996 owing to inferior results.

\section{RESULTS}

For the final analysis, 1195 of 1201 patients could be evaluated: 260 in the COPP-ABVD group, 469 in the BEACOPP group, and 466 in the increased-dose BEACOPP group; the median follow-up was 72, 54, and 51 months, respectively. The rate of freedom from treatment failure at five years was 69 percent in the COPP-ABVD group, 76 percent in the BEACOPP group, and 87 percent in the increased-dose BEACOPP group $(\mathrm{P}=0.04$ for the comparison of the COPP-ABVD group with the BEACOPP group and $\mathrm{P}<0.001$ for the comparison of the increased-dose BEACOPP group with the COPP-ABVD group and with the BEACOPP group), and the five-year rates of overall survival were 83 percent, 88 percent, and 91 percent, respectively $(\mathrm{P}=0.16$ for the comparison of the COPP-ABVD group with the BEACOPP group, $\mathrm{P}=0.06$ for the comparison of the BEACOPP group with the increased-dose BEACOPP group, and $\mathrm{P}=0.002$ for the comparison of the COPP-ABVD group with the increased-dose BEACOPP group). Rates of early progression were significantly lower with increased-dose BEACOPP than with COPP-ABVD or standard BEACOPP.

CONCLUSIONS

Increased-dose BEACOPP resulted in better tumor control and overall survival than did COPP-ABVD. 
T

HE STANDARD CHEMOTHERAPY COMbinations for advanced Hodgkin's disease are mechlorethamine, vincristine, procarbazine, and prednisone (MOPP) and doxorubicin, bleomycin, vinblastine, and dacarbazine (ABVD), ${ }^{1-5}$ yet 30 to 40 percent of cases progress or relapse and respond poorly to salvage treatment.6,7 In 1990 the German Hodgkin's Lymphoma Study Group planned a sequence of clinical trials on the basis of results of experiments in animals, retrospective analyses of clinical data, and mathematical models $^{8,9}$ suggesting that more rapid administration could improve the disease-free survival rate by 3 percent and that a moderate dose escalation could improve this rate by an additional 10 percent. ${ }^{10,11}$ Our trial compared three regimens: COPP-ABVD (with cyclophosphamide instead of mechlorethamine); a combination of bleomycin, etoposide, doxorubicin, cyclophosphamide, vincristine, procarbazine, and prednisone (BEACOPP) in standard doses; and BEACOPP in increased doses.

Pilot and dose-finding studies confirmed the feasibility of BEACOPP and of the escalation of the doses of cyclophosphamide, etoposide, and doxorubicin to 192,200 , and 140 percent of the standard doses, respectively. ${ }^{12,13}$ The phase 3 trial aimed to assess the efficacy and toxicity of standard and increased-dose BEACOPP. Interim analyses have demonstrated the effectiveness of BEACOPP. ${ }^{14,15} \mathrm{We}$ present the results of the final data analysis as of August 2001.

\section{METHODS}

\section{PATIENTS}

Eligible patients were 15 to 65 years old with newly diagnosed, untreated Hodgkin's disease in Ann Arbor clinical stage IIB or IIIA with a large mediastinal mass (more than one third of the maximal thoracic diameter) alone or in combination with extranodal lesions or massive splenic involvement (with diffuse infiltration or more than five focal lesions, as determined by computed tomography and sonography) or both; stage IIIA with an elevated erythrocyte sedimentation rate (more than $50 \mathrm{~mm}$ per hour in asymptomatic patients and more than $30 \mathrm{~mm}$ per hour in patients with B symptoms) or three or more involved nodal areas, or both; or Stage IIIB or IV. Patients had to have a Karnofsky index above 70 percent, to be negative for the human immunodeficiency virus, to be free of concurrent disease that might hinder treatment, and to give written informed con- sent. Patients were registered and treated in 219 hospitals and practices in Germany, Switzerland, Austria, and the Czech Republic (listed in the Appendix). Review of biopsy specimens by a panel of lymphoma pathologists was an obligatory part of the protocol.

\section{STUDY DESIGN}

After clinical staging had been conducted according to previously reported methods, ${ }^{14}$ patients were randomly assigned (in a centralized, open fashion by telephone and by computer) to one of three chemotherapy regimens: eight cycles of COPP alternating with ABVD; eight cycles of standarddose BEACOPP; or eight cycles of increased-dose BEACOPP, with the administration of filgrastim from day 8 of each cycle until the leukocyte count returned to normal (Table 1). Randomization was stratified (i.e., balance among the groups was maintained) according to the participating center, tumor stage (IIB or IIIA vs. IIIB or IV), and the presence or absence of a large mediastinal mass.

For the increased-dose BEACOPP group, the dose could be reduced in subsequent cycles if pre-

\begin{tabular}{|c|c|c|c|c|c|c|}
\hline \multirow[t]{3}{*}{ Drug } & \multicolumn{2}{|c|}{ COPP-ABVD } & \multicolumn{2}{|c|}{$\begin{array}{l}\text { Standard } \\
\text { BEACOPP }\end{array}$} & \multicolumn{2}{|c|}{$\begin{array}{l}\text { Increased-Dose } \\
\text { BEACOPP }\end{array}$} \\
\hline & $\begin{array}{l}\text { Single } \\
\text { Dose }\end{array}$ & $\begin{array}{l}\text { Days } \\
\text { Given* }\end{array}$ & $\begin{array}{l}\text { Single } \\
\text { Dose }\end{array}$ & $\begin{array}{l}\text { Days } \\
\text { Given't }\end{array}$ & $\begin{array}{l}\text { Single } \\
\text { Dose }\end{array}$ & $\begin{array}{l}\text { Days } \\
\text { Given } †\end{array}$ \\
\hline & $\mathrm{mg} / \mathrm{m}^{2}$ & & $\mathrm{mg} / \mathrm{m}^{2}$ & & $\mathrm{mg} / \mathrm{m}^{2}$ & \\
\hline Bleomycin & 10 & 29,43 & 10 & 8 & 10 & 8 \\
\hline Etoposide & - & - & 100 & $1-3$ & 200 & $1-3$ \\
\hline Doxorubicin & 25 & 29,43 & 25 & 1 & 35 & 1 \\
\hline Cyclophosphamide & 650 & 1,8 & 650 & 1 & 1200 & 1 \\
\hline Vincristine & $1.4 \nmid$ & 1,8 & $1.4 \nmid$ & 8 & $1.4 \dagger$ & 8 \\
\hline Procarbazine & 100 & $1-14$ & 100 & $1-7$ & 100 & $1-7$ \\
\hline Prednisone & 40 & $1-14$ & 40 & $1-14$ & 40 & $1-14$ \\
\hline Vinblastine & 6 & 29,43 & - & - & - & - \\
\hline Dacarbazine & 375 & 29,43 & - & - & - & - \\
\hline
\end{tabular}


defined toxic effects - World Health Organization (WHO) grade 4 (life-threatening) leukopenia for more than four days; WHO grade 4 thrombocytopenia, infection, or mucositis; or an adverse effect that required a two-week delay in treatment occurred in a given cycle. ${ }^{13}$ After each such event, the doses of cyclophosphamide and etoposide were reduced by one level on a five-level scale ranging from standard to escalated doses; if toxic effects occurred in two successive cycles, standard doses were used for all subsequent cycles. The tumor stage was reevaluated after four and eight cycles by means of a clinical examination and imaging or biopsy methods appropriate to the site of initial involvement (computed tomography, sonography, bone scintigraphy, bone marrow biopsy, or liver biopsy). After the completion of chemotherapy, sites of initial bulky disease (those at least $5 \mathrm{~cm}$ in diameter) received 30 Gy of irradiation and any residual tumor received $40 \mathrm{~Gy}$. Inactive sites that were apparently treatment-related artifacts were considered to be part of a complete remission and were not irradiated. The outcome of treatment was assessed three months after the completion of the protocol.

\section{STATISTICAL ANALYSIS}

The primary end point of the trial was freedom from treatment failure, with progression during treatment, lack of complete remission at the end of protocol treatment, relapse, and death from any cause counted as adverse events. The rate of overall survival and the outcome of treatment (complete remission or early progression) were secondary end points. The rates of freedom from treatment failure and overall survival were compared between groups with use of the Kaplan-Meier method and the logrank test, whereas outcomes were compared with use of the chi-square test (all methods were prespecified).

The trial was designed to test the hypotheses

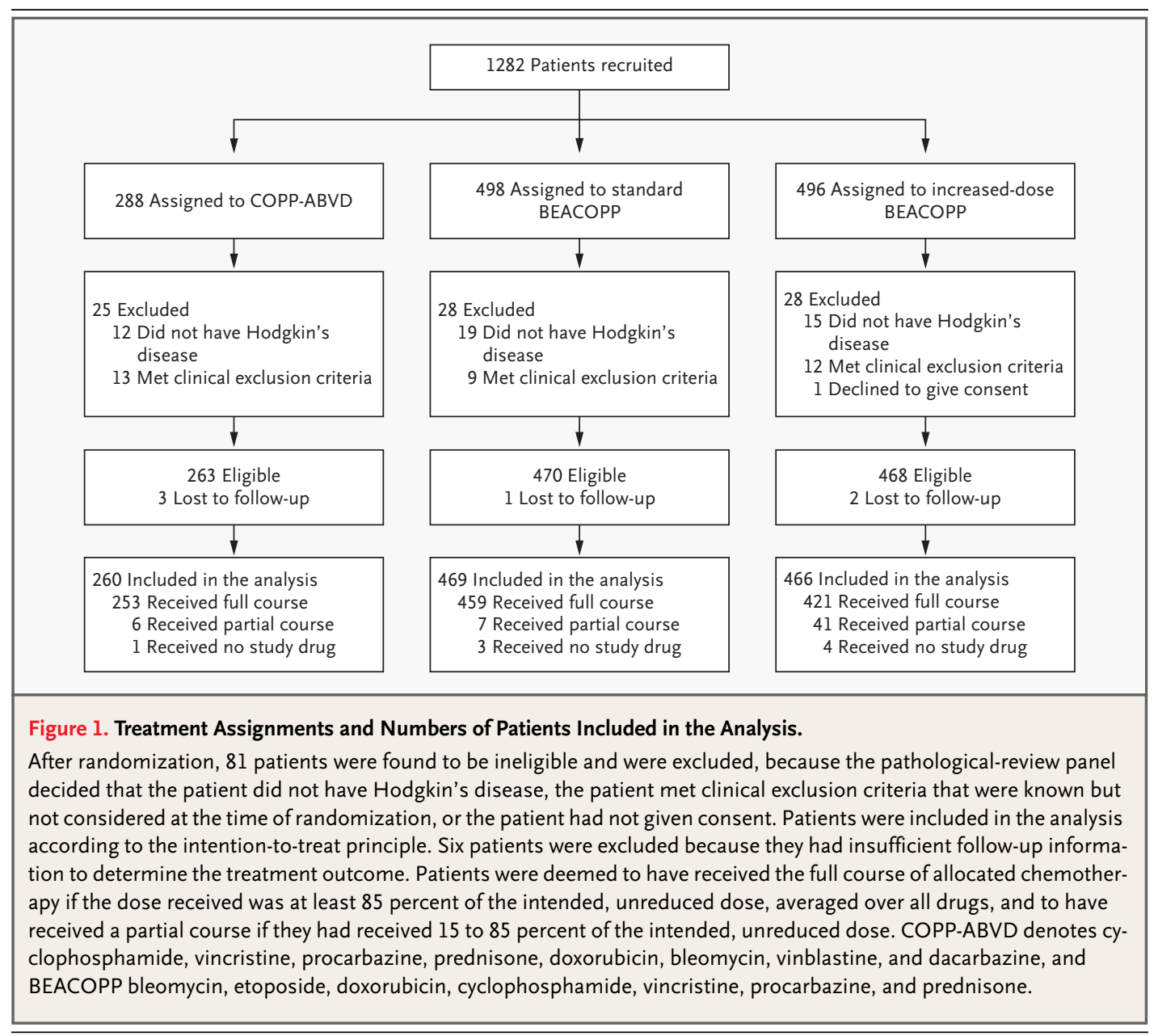


that BEACOPP (irrespective of the dose) results in a higher rate of freedom from treatment failure than COPP-ABVD and that increased-dose BEACOPP results in a higher rate of freedom from treatment failure than standard BEACOPP. For the study to have a statistical power of 80 percent to detect an absolute difference of 9 to 10 percent in either of these comparisons, we determined that 900 patients would have to be enrolled. All analyses were conducted according to the intention-to-treat principle, with the proviso that patients for whom an exclusion criterion was discovered after randomization, on the basis of a clinical examination or examination of biopsy material obtained before randomization, would be excluded as ineligible.

The study design called for interim analyses after $2,3,4$, and 5 years and a final analysis after $71 / 2$ years. We used a truncated sequential probability ratio strategy as proposed by Whitehead (nominal alpha of 0.1 , with 80 percent power to detect a hazard ratio of 0.7 for both BEACOPP groups together as compared with the COPP-ABVD group) to determine whether the trial should be stopped early. ${ }^{16}$ All tests were two-sided, and P values were not adjusted for sequential analysis.

\section{RESULTS}

Recruitment began in February 1993 and ended in March 1998. Random assignment to the increaseddose BEACOPP group began after the completion of the dose-finding study in 1994; subsequently, unequal randomization probabilities were used to equalize the numbers in each group. At the first interim analysis in September 1996, the early stopping boundary was crossed, with the demonstration that both BEACOPP groups together were significantly superior to COPP-ABVD in terms of the rate of freedom from treatment failure $(\mathrm{P}=0.03$, adjusted for Whitehead sequential analysis). ${ }^{14}$ Therefore, assignment to the COPP-ABVD group was stopped. Assignments to the other two groups were increased so that each group would include 500 patients, thus permitting a more precise comparison of the groups. We then used a group sequential design according to the method of Peto to determine whether early-stopping criteria were met in the BEACOPP groups.

The final analysis was completed in August 2001. Of the 1282 patients we enrolled, 81 were subsequently found to be ineligible, because of the wrong diagnosis in 46 , concurrent disease in 8 , incorrect staging in 10 , other clinical exclusion criteria in 16 , and lack of informed consent from 1 (Fig. 1). All but 6 of the 1201 eligible patients had sufficient data to determine the outcome of treatment. There were 260 patients in the COPP-ABVD group (assignment to this group was stopped early), 469 in the standard BEACOPP group, and 466 in the increased-dose BEACOPP group. The characteristics of the patients were balanced among the three groups (Table 2).

The incidence of acute hematologic effects was similar in the COPP-ABVD and standard BEACOPP groups but was greatly increased in the increaseddose BEACOPP group (Table 3). In this group, grade 3 and 4 leukopenia was common in all eight cycles,

Table 2. Characteristics of the Patients *

\begin{tabular}{|c|c|c|c|}
\hline Characteristic & $\begin{array}{l}\text { COPP. } \\
\text { ABVD } \\
(\mathrm{N}=260)\end{array}$ & $\begin{array}{c}\text { Standard } \\
\text { BEACOPP } \\
\text { (N=469) }\end{array}$ & $\begin{array}{l}\text { Increased-Dose } \\
\text { BEACOPP } \\
(\mathrm{N}=466)\end{array}$ \\
\hline $\begin{array}{l}\text { Age } \\
\text { 50-65 yr (\%) } \\
\text { Median (yr) }\end{array}$ & $\begin{array}{l}16 \\
32.1\end{array}$ & $\begin{array}{l}18 \\
32.7\end{array}$ & $\begin{array}{l}15 \\
31.5\end{array}$ \\
\hline Male sex (\%) & 57 & 63 & 62 \\
\hline $\begin{array}{l}\text { Histologic review (\%) } \dagger \\
\text { Lymphocyte predominant/LRCHD } \\
\text { Nodular sclerosis } \\
\text { Mixed cellularity } \\
\text { Lymphocyte depletion } \\
\text { Unclassified or diagnosis of } \\
\text { Hodgkin's disease uncertain }\end{array}$ & $\begin{array}{r}6 \\
61 \\
23 \\
2 \\
8\end{array}$ & $\begin{array}{r}4 \\
64 \\
20 \\
3 \\
9\end{array}$ & $\begin{array}{r}4 \\
69 \\
18 \\
2 \\
8\end{array}$ \\
\hline $\begin{array}{l}\text { Clinical or pathological stage (\%) } \\
\text { IIB } \\
\text { IIIA } \\
\text { IIIB } \\
\text { IVA } \\
\text { IVB } \\
\text { Laparotomy performed }\end{array}$ & $\begin{array}{r}9 \\
31 \\
29 \\
9 \\
23 \\
9\end{array}$ & $\begin{array}{r}14 \\
24 \\
28 \\
9 \\
26 \\
6\end{array}$ & $\begin{array}{r}16 \\
21 \\
31 \\
10 \\
23 \\
5\end{array}$ \\
\hline Bulky disease (\%) $\ddagger$ & 58 & 68 & 67 \\
\hline $\begin{array}{l}\text { International prognostic index (\%)』 } \\
0-1 \\
2-3 \\
4-7\end{array}$ & $\begin{array}{l}28 \\
38 \\
13\end{array}$ & $\begin{array}{l}22 \\
41 \\
16\end{array}$ & $\begin{array}{l}28 \\
38 \\
13\end{array}$ \\
\hline
\end{tabular}

* Because of rounding, percentages may not total 100. COPP-ABVD denotes cyclophosphamide, vincristine, procarbazine, prednisone, doxorubicin, bleomy cin, vinblastine, and dacarbazine; BEACOPP bleomycin, etoposide, doxorubicin, cyclophosphamide, vincristine, procarbazine, and prednisone; and LRCHD lymphocyte-rich classic Hodgkin's disease.

$\dagger$ Data were available for 76 percent of patients: 72 percent of patients in the COPP-ABVD group, 76 percent in the standard BEACOPP group, and 77 percent in the increased-dose BEACOPP group.

$†$ Bulky disease was defined as a mass that was at least $5 \mathrm{~cm}$ in diameter.

$\int$ The international prognostic index was calculated according to the method of Hasenclever and Diehl. ${ }^{17} \mathrm{~A}$ score of 0 indicates the absence of all adverse prognostic factors, and a score of 7 the presence of all adverse prognostic factors. Data were available for 79 percent of patients in each group. 


\begin{tabular}{|c|c|c|c|}
\hline \multicolumn{4}{|c|}{ Table 3. Acute Adverse Effects of Chemotherapy.* } \\
\hline Adverse Effect & $\begin{array}{l}\text { COPP- } \\
\text { ABVD }\end{array}$ & $\begin{array}{r}\text { Standard } \\
\text { BEACOPP } \\
\text { percer }\end{array}$ & $\begin{array}{l}\text { Increased-Dose } \\
\text { BEACOPP } \\
n t\end{array}$ \\
\hline $\begin{array}{r}\text { Leukopenia } \\
\text { Grade } 3 \\
\text { Grade } 4\end{array}$ & $\begin{array}{l}52 \\
19\end{array}$ & $\begin{array}{l}36 \\
37\end{array}$ & $\begin{array}{r}8 \\
90\end{array}$ \\
\hline $\begin{array}{l}\text { Thrombocytopenia } \\
\text { Grade } 3 \\
\text { Grade } 4\end{array}$ & $\begin{array}{l}4 \\
2\end{array}$ & $\begin{array}{l}6 \\
3\end{array}$ & $\begin{array}{l}23 \\
47\end{array}$ \\
\hline $\begin{array}{l}\text { Anemia } \\
\text { Grade } 3 \\
\text { Grade } 4\end{array}$ & $\begin{array}{l}4 \\
1\end{array}$ & $\begin{array}{r}16 \\
1\end{array}$ & $\begin{array}{l}51 \\
15\end{array}$ \\
\hline $\begin{array}{l}\text { Infection } \\
\text { Grade } 3 \\
\text { Grade } 4\end{array}$ & $\begin{array}{l}2 \\
1\end{array}$ & $\begin{array}{r}13 \\
3\end{array}$ & $\begin{array}{r}14 \\
8\end{array}$ \\
\hline Mucositis of grade 3 or 4 & 1 & 2 & 8 \\
\hline Respiratory tract effects of grade 3 or 4 & 2 & 5 & 4 \\
\hline Nausea of grade 3 or 4 & 20 & 12 & 20 \\
\hline Digestive tract effects of grade 3 or 4 & 3 & 2 & 4 \\
\hline Neurologic effects of grade 3 or 4 & 4 & 5 & 4 \\
\hline Skin effects of grade 3 or 4 & 1 & 1 & 3 \\
\hline Pain of grade 3 or 4 & 2 & 3 & 9 \\
\hline Hair loss of grade 3 or 4 & 36 & 75 & 79 \\
\hline
\end{tabular}

* The values are the percentages of patients with the given World Health Organization (WHO) grade adverse effect in one or more cycles. The frequencies of WHO grade 3 or 4 cardiac toxicity, medication-induced fever, renal or urinary effects, and allergies were all below 2 percent in each group. COPP-ABVD denotes cyclophosphamide, vincristine, procarbazine, prednisone, doxorubicin, bleomycin, vinblastine, and dacarbazine, and BEACOPP bleomycin, etoposide, doxorubicin, cyclophosphamide, vincristine, procarbazine, and prednisone.

whereas the frequency of thrombocytopenia and anemia increased during the last four cycles. Grade 3 or 4 infections occurred in 16 percent of patients in the standard BEACOPP group and 22 percent of those in the increased-dose BEACOPP group. The incidence of fatal acute treatment-related effects was similar (less than 2 percent) among the groups. A detailed report of the acute hematologic effects and administered doses has been published previously. ${ }^{18}$

Between 73 percent and 99 percent of patients received at least 80 percent of the planned total dose. In the increased-dose BEACOPP group, the doses of cyclophosphamide gradually decreased, from 192 percent of the planned standard dose in the first cycle to 148 percent of this dose in the eighth cycle; similar trends were observed for etoposide (from
198 percent initially to 152 percent) and doxorubicin (from 139 percent initially to 126 percent). The median duration of chemotherapy from the first to the last day of drug administration was 46.3 weeks in the COPP-ABVD group (planned, 30 weeks), 24.4 weeks in the BEACOPP group (planned, 23 weeks), and 24.7 weeks in the increased-dose BEACOPP group (planned, 23 weeks). The percentage of patients who received radiotherapy was 64 percent in the COPP-ABVD group and 71 percent in the other two groups.

Progression occurred in 27 of 260 patients in the COPP-ABVD group (10 percent) during or up to three months after treatment, 36 of 469 in the BEACOPP group (8 percent), and 9 of 466 in the increased-dose BEACOPP group (2 percent); the difference between the two BEACOPP groups was significant $(\mathrm{P}<0.001)$, as was that between increaseddose BEACOPP and COPP-ABVD $(\mathrm{P}<0.001)$. The rate of complete remission was higher in the the two BEACOPP groups than in the COPP-ABVD group (Table 4). The median follow-up was 72 months in the COPP-ABVD group, 54 months in the standard BEACOPP group, and 51 months in the increaseddose BEACOPP group (follow-up was longer in the COPP-ABVD group because enrollment was stopped early). The rate of freedom from treatment failure was significantly higher at five years in the standard BEACOPP group than in the COPP-ABVD group $(76$ percent $[95$ percent confidence interval, 72 to 80 percent] vs. 69 percent [ 95 percent confidence interval, 63 to 75 percent], $\mathrm{P}=0.04$ ) and was highest in the increased-dose BEACOPP group $(87$ percent [ 95 percent confidence interval, 83 to 91 percent], $\mathrm{P}<0.001$ for the comparison with the COPP-ABVD group and with the standard BEACOPP group) (Fig. 2A and Table 4).

The deaths of 150 patients have been reported to us: 49 in the COPP/ABVD group, 61 in the standard BEACOPP group, and 40 in the increased-dose BEACOPP group. The overall survival rate (Fig. 2B and Table 4) was higher in the standard BEACOPP group than in the COPP-ABVD group at five years (88 percent vs. 83 percent, $\mathrm{P}=0.16$ ) and was highest in the increased-dose BEACOPP group (91 percent, $\mathrm{P}=0.06$ for the comparison with the standard BEACOPP group and $\mathrm{P}=0.002$ for the comparison with the COPP-ABVD group). The causes of death were recorded as Hodgkin's disease in 68 patients, complications of first-line treatment in 20, complications of salvage treatment in 14 , a second neoplasm in 22 , cardiorespiratory disease in 5 , pulmo- 
nary disease in 4 , other causes in 9 , and unknown causes in 8 . Fatal acute treatment-related adverse effects included sepsis in 11 patients (including 2 with the acute respiratory distress syndrome), pneumonia in 5 , and thrombosis in 1 ; no details were available in the case of 3 patients.

To assess the efficacy of the three treatments according to the prognosis, the patients were divided into three subgroups on the basis of the international prognostic index. ${ }^{17}$ Owing to missing data, the score was unavailable for 56 patients in the COPPABVD group, 100 in the BEACOPP group, and 99 in the increased-dose BEACOPP group (21 percent of all patients). The rates of early progression, five-year freedom from treatment failure, and overall survival at five years for the three subgroups are shown in Table 5 . Within each of the three groups, the score for the international prognostic index consistently correlated with the rates of early progression and fiveyear freedom from treatment failure. Within each prognostic subgroup, standard and increased-dose BEACOPP resulted in lower rates of early progression and higher rates of freedom from treatment failure and overall survival than did COPP-ABVD. There was no indication of a statistical interaction between the treatment group and the prognostic group $(\mathrm{P}=0.91$ for the interaction term in a Cox regression model). Furthermore, all age groups seemed to benefit from standard and increaseddose BEACOPP, with the possible exception of those who were 60 to 65 years of age (data not shown). In this group of 64 patients, there were no significant differences between the treatment groups $(\mathrm{P}=0.93)$.

Cases of secondary acute leukemia including the myelodysplastic syndrome occurred in one patient in the COPP-ABVD group, four in the standard BEACOPP group, and nine in the increased-dose BEACOPP group. The actuarial rate of secondary acute leukemias five years after the diagnosis of Hodgkin's disease (according to a Kaplan-Meier analysis) was 0.4 percent in the COPP-ABVD group, 0.6 percent in the BEACOPP group, and 2.5 percent in the increased-dose BEACOPP group ( $\mathrm{P}=0.03)$. Solid tumors were recorded in three, eight, and two patients, respectively, and second non-Hodgkin's lymphomas in seven, four, and five patients, respectively.

\section{I SCUSSION}

Our results indicate that in patients with newly diagnosed advanced Hodgkin's lymphoma, increased-

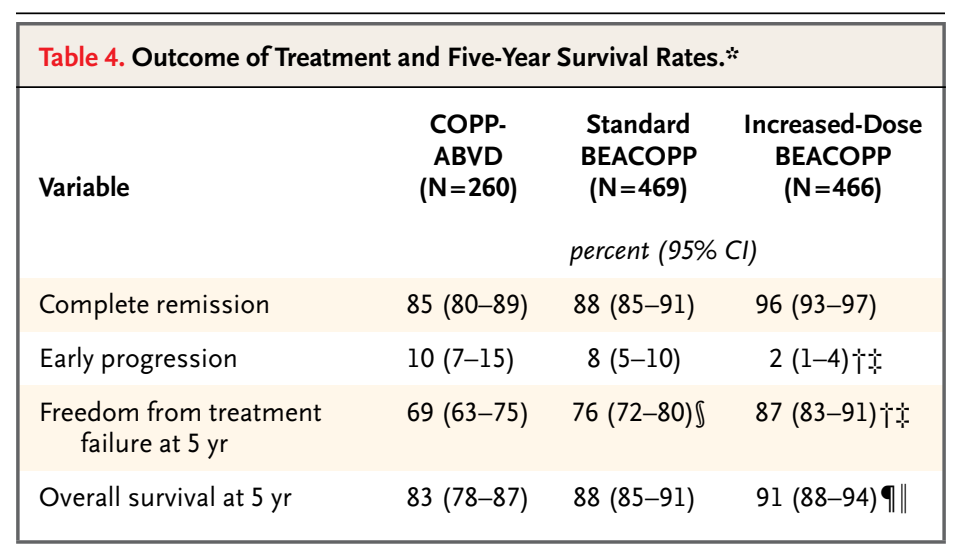

* COPP-ABVD denotes cyclophosphamide, vincristine, procarbazine, prednisone, doxorubicin, bleomycin, vinblastine, and dacarbazine; BEACOPP bleomycin, etoposide, doxorubicin, cyclophosphamide, vincristine, procarbazine, and prednisone; and $\mathrm{Cl}$ confidence interval. Early progression was defined as progression of disease during treatment or within three months after the end of treatment.

$\uparrow \mathrm{P}<0.001$ for the comparison with the COPP-ABVD group.

$P<0.001$ for the comparison with the standard BEACOPP group

$\int P=0.04$ for the comparison with the COPP-ABVD group.

I $P=0.002$ for the comparison with the COPP-ABVD group.

$\| \mathrm{P}=0.06$ for the comparison with the standard BEACOPP group.

dose BEACOPP is superior to COPP-ABVD with respect to failure-free survival (18 percentage points better at five years) and overall survival (8 percentage points better). The rate of early progression was 10 percent in the COPP-ABVD group and 2 percent in the increased-dose BEACOPP group. The difference in efficacy between increased-dose and standard BEACOPP appears to be larger than the difference between standard BEACOPP and COPP-ABVD. In terms of overall survival, by contrast, the results of pairwise group comparisons were not significantly different. However, projections based on observed rates of progression, relapse, toxic effects, and second cancers suggest that increased-dose BEACOPP confers a small, long-term survival benefit. ${ }^{19}$ The incidence of acute toxicity increased with increased-dose BEACOPP; grade 4 leukopenia occurred in one or more cycles in 90 percent of patients. However, these events were manageable, as indicated by the numbers of deaths, the duration of chemotherapy, and the drug doses administered. ${ }^{18}$ The multicenter setting of the trial, which included local hospitals and private practices, indicates that a regimen of increased-dose BEACOPP is generally feasible. All prognostic groups seemed to benefit from BEACOPP and from dose escalation.

Since the recruitment periods for the three treatment groups were not identical, a shift in the characteristics of the patients during the trial could have 


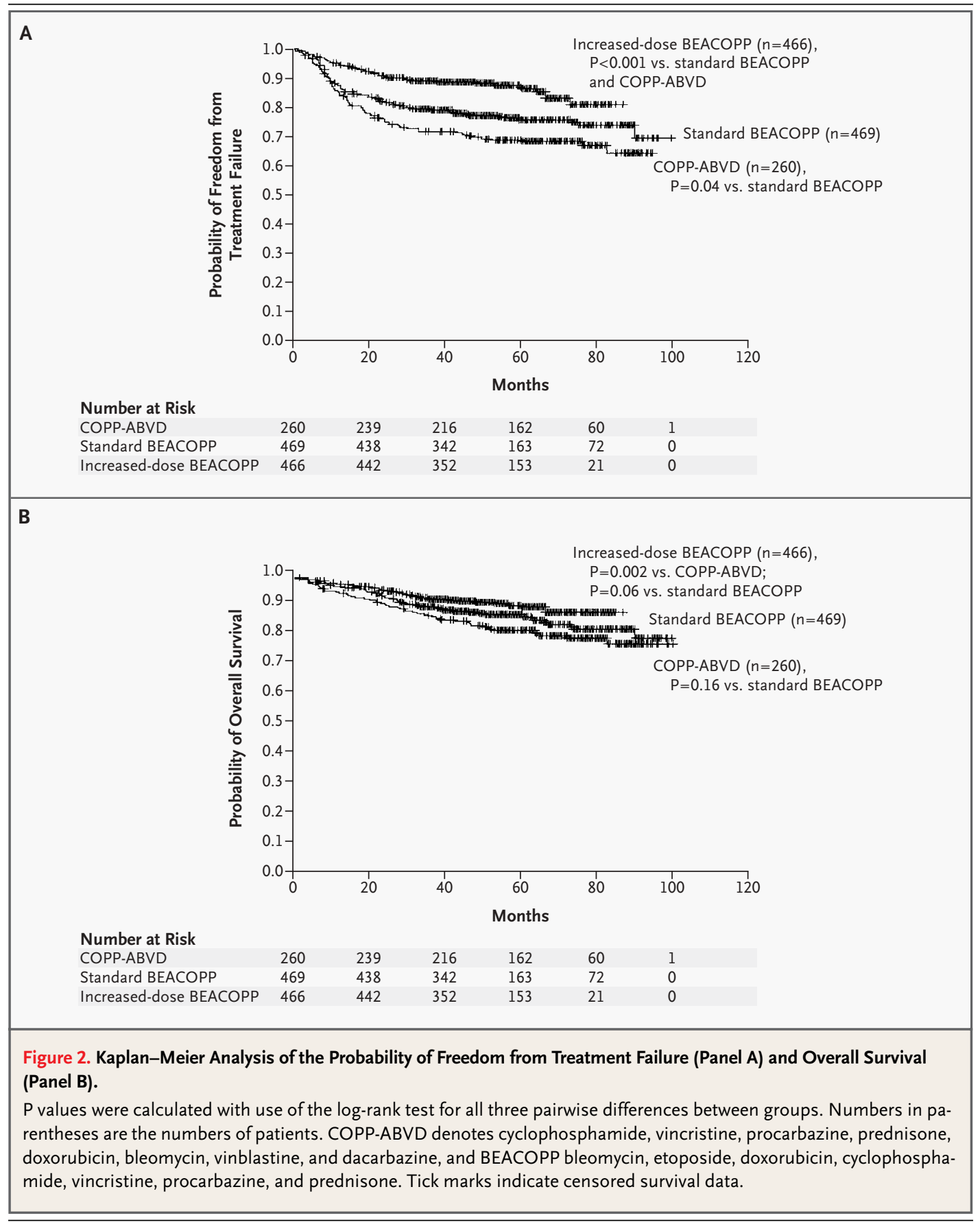

resulted in bias. We compared these characteristics among the three groups in each recruitment year but found no relevant differences or consistent trends over time. We repeated all group comparisons for the period from February 1994 through October 1996, during which patients were recruited for all three groups, and obtained results similar to those reported above.
Other randomized trials have demonstrated that the efficacy of MOPP-ABVD; hybrid MOPP plus doxorubicin, bleomycin, and vinblastine (MOPP-ABV); and ABVD is similar, with long-term (5 to 10 years) progression-free survival rates of 61 to 71 percent. ${ }^{1,2}$ Numerous variants of these regimens have been tested, ${ }^{3-5}$ but none have improved treatment efficacy. In contrast, the estimated rate of free- 
dom from treatment failure with increased-dose BEACOPP is currently estimated as 89 percent at three years and 87 percent at five years.

Three reports of interim results, however, compare favorably with our results for increased-dose BEACOPP. A five-year progression-free survival rate of 89 percent was achieved with the Stanford V regimen (mechlorethamine, doxorubicin, etoposide, vincristine, vinblastine, bleomycin, and prednisone), ${ }^{20}$ an event-free survival rate of 82 percent was obtained at five years by the European Organization for Research and Treatment of Cancer with the MOPP-ABV regimen, ${ }^{21}$ and a progression-free survival rate of 82 percent at five years was reported with a hybrid regimen consisting of six courses of chlorambucil, vinblastine, procarbazine, prednisone, etoposide, vincristine, and doxorubicin followed by local irradiation. ${ }^{22}$

That the proportion of our patients who received radiotherapy was greater in the two BEACOPP groups (71 percent) than in the COPP-ABVD group (64 percent) can largely be attributed to the greater incidence of initial bulky disease in these groups (68 percent in the BEACOPP group and 67 percent in the increased-dose BEACOPP group, as compared with 58 percent in the COPP-ABVD group), which itself was presumably due to chance. Furthermore, the shorter planned duration of BEACOPP therapy ( 24 weeks, as compared with 32 weeks for COPPABVD) allows less time for residual tumor to shrink.

The occurrence of nine cases of acute leukemia after increased-dose BEACOPP seems alarming, especially as compared with the low leukemogenicity of the ABVD regimen. ${ }^{23,24}$ However, this complication must be weighed against the lower rate of early progression and higher rates of failure-free survival and overall survival rates at five years, ${ }^{25}$ and with the fact that secondary leukemias are likely to be induced in later years as a result of treatment for early progression or relapse. ${ }^{26,27}$ Further study is needed before a reliable assessment of the long-term risks of standard and increased-dose BEACOPP can be made.

Reliable data on the long-term gonadal toxicity of BEACOPP are not available, but it should be assumed that, as is the case with COPP-ABVD and similar regimens, a high proportion of patients, male and female, will become infertile. ${ }^{28}$ This disadvantage is shared by MOPP-containing regimens but not by those that include ABVD, since such regimens largely preserve male fertility. ${ }^{29}$ The impor-

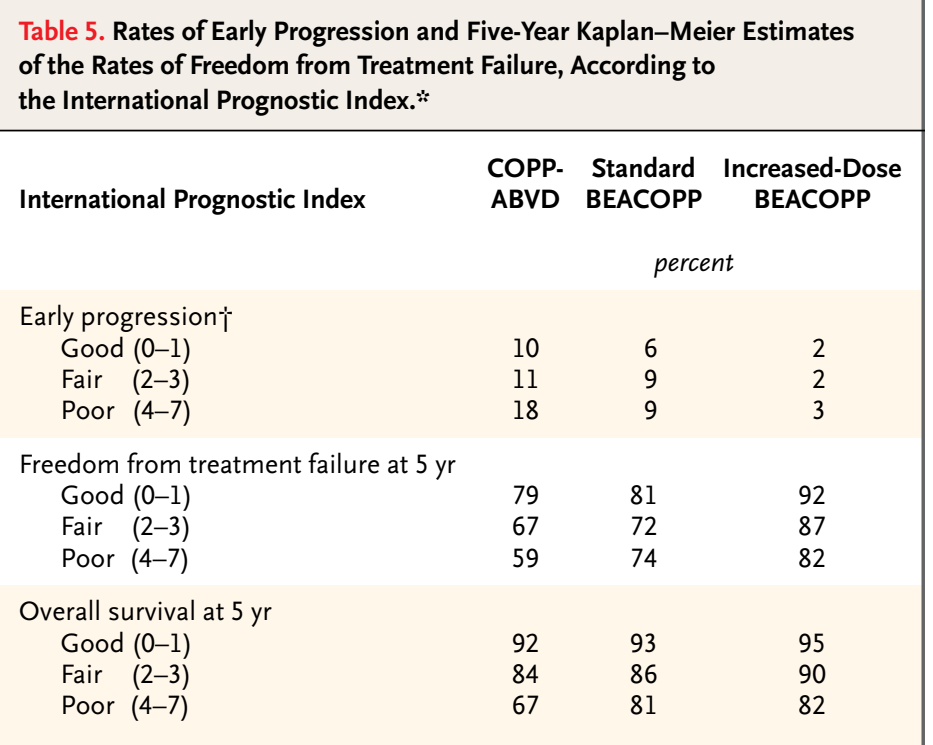

* A score of 0 indicates the absence of all adverse prognostic factors, and a score of 7 the presence of all adverse prognostic factors. A total of 306 patients had a score of 0 to 1,465 had a score of 2 to 3,169 had a score of 4 to 5 , and 255 had unknown scores. COPP-ABVD denotes cyclophosphamide, vincristine, procarbazine, prednisone, doxorubicin, bleomycin, vinblastine, and dacarbazine, and BEACOPP bleomycin, etoposide, doxorubicin, cyclophosphamide, vincristine, procarbazine, and prednisone.

$\dagger$ Early progression was defined as progression of disease during treatment or within three months after the end of treatment.

tance of this aspect must be weighed against the avoidance of progression and relapse of advanced disease in each patient. Infertility after therapy may be compensated for by the use of cryopreservation techniques before therapy. ${ }^{30}$

Increased-dose BEACOPP therapy is more expensive than COPP-ABVD, given the direct medical costs of inpatient stays, chemotherapy drugs, and filgrastim. Nevertheless, the incremental cost-effectiveness ratio with respect to the gain in overall survival appears to be favorable. ${ }^{31}$

In conclusion, our results suggest that both BEACOPP and the principle of a moderate filgrastim-supported escalation in the dose are promising treatment strategies for advanced Hodgkin's disease. Increased-dose BEACOPP is an attractive treatment option for adults up to about 60 years of age. The need for consolidation radiotherapy, which was administered to 71 percent of patients after BEACOPP, remains unproved ${ }^{32}$ and is being investigated. ${ }^{33}$

Supported by a grant from the Deutsche Krebshilfe and by the Swiss Group for Clinical Cancer Research. 
APPENDIX

The following persons were responsible for the trial: Chairman — V. Diehl (University of Cologne, Cologne, Germany); Coordinators - B. Lathan, M. Pfreundschuh, and H. Tesch (University of Cologne, Cologne, Germany); Central monitoring - H. Nisters-Backes and T. Koch (University of Cologne, Cologne, Germany); Data management - T. Schober (University of Cologne, Cologne, Germany); Statistical analysis - J. Franklin and U. Paulus (University of Cologne, Cologne, Germany), D. Hasenclever and M. Loeffler (University of Leipzig, Leipzig, Germany); Pathology review - A. Georgii (Hannover Medical School, Hannover, Germany) and H.-C. Mueller-Hermelink (University of Frankfurt, Frankfurt, Germany); and Radiotherapy review - E. Duehmke (University of Munich, Munich, Germany).

The following participating institutions recruited at least three patients into the study and are listed in descending order of the numbers recruited (clinics are in Germany unless otherwise noted): Bern, Switzerland, Swiss Group for Clinical Cancer Research (centers in Bern, Basel, Lausanne, St. Gallen, and Ticino); Berlin, Universitäts-Klinikum Charité, Innere Medizin; Münster, Universitäts-Klinik, Onkologische Ambulanz 15 A West; Köln, Universitäts-Klinik, Klinik I für Innere Medizin, Ambulanz; Chemnitz, Klinikum Chemnitz/Krankenhaus Küchwald, Klinik für Hämatologie Station 271; Göttingen, Georg-August-Universität, Medizinische Klinik Abteilung Hämatologie/Onkologie; Stuttgart, Robert-Bosch-Krankenhaus, Innere Medizin II Hämatologie/Onkologie; Homburg, Medizinische Universitäts-Klinik, Innere Medizin. I; Karlsruhe, Städtisches Klinikum, Medizinische Klinik II/Hämatologie; Berlin, Universitäts-Klinikum Charité Mitte, Hämatologie/ Onkologie; Kiel, Städtisches Klinikum der Christian-Albrechts-Universität, II. Medizinische Klinik; Heidelberg, Universitäts-Klinikum, Medizinische Klinik und Poliklinik V; Nürnberg, Klinikum, Klinik V Onkologie/Hämatologie; Magdeburg, Otto v. Guericke Universität, Abteilung für Hämatologie; Karlsruhe, St. Vincentius Krankenhäuser, Zentrum für Innere Medizin; Regensburg, Universitäts-Klinik, Klinik I für Innere Medizin; Freiburg, Medizinische Universitäts-Klinik, Innere Medizin I, Abteilung Hämatologie/Onkologie; Gießen, JustusLiebig-Universität, Innere Medizin Hämatologie/Onkologie; Heidelberg, Thorax-Klinik der LVA Baden, Internistisch-Onkologische Abteilung; Prague, Czech Republic, Fakultni Nemocnice, Oddelení klinické hematologia; Braunschweig, Städtisches Klinikum, Medizinische Klinik; Marburg, Klinikum der Philipps-Universität, Innere Medizin Hämatologie/Onkologie; Essen, Universitäts-Klinik, Hämatologische Tagesklinik; Hannover, Dr. Wysk, Hämatologische/Onkologische Gemeinschaftspraxis; Hamburg, Universität Krankenhaus Eppendorf, Abteilung Hämatologie/Onkologie; Würzburg, Universitäts-Klinik und Poliklinik, Onkologische Abteilung; Minden, Klinikum, Abteilung Hämatologie/Onkologie; Erlangen, Universitäts-Klinik, Medizinische Klinik und Poliklinik III; Lübeck, Städtisches Krankenhaus Süd, Abteilung Hämatologie/Onkologie; Lübeck, Medizinische Universität, Innere Medizin Hämatologie/Onkologie; Dresden, UniversitätsKlinik C.G. Carus, Medizinische Klinik I; München, Klinikum "Rechts der Isar," Medizinische Klinik III; Saarbrücken, Caritasklinik St. Theresia, Klinik für Onkologie und Immunologie; Krefeld, Städtische Krankenanstalten, Medizinische Klinik II; Offenburg, Klinikum, Medizinische Klinik II; Tübingen, Eberhard-Karls-Universität, Abteilung Innere Medizin II Hämatologische Ambulanz; Jena, FriedrichSchiller-Universität, Klinik für Innere Medizin; Bayreuth, Klinikum, Medizinische Klinik I; Stuttgart, Bürgerhospital, Medizinische Klinik I; Essen, Evangelisches Krankenhaus, Innere Medizin; Heilbronn, Städtisches Krankenhaus, I. Medizinische Klinik; Hamm, Ev. Krankenhaus, Innere Medizin/Hämatologie/Onkologie; Darmstadt, Städtische Kliniken, Medizinische Klinik V/Hämatologie; Dortmund, St. Johannes Hospital, Medizinische Klinik; München, Akademisches Lehrkrankenhaus, I. Medizinische Abteilung; Eschweiler, St. Antonius Hospital, Abteilung für Hämatologie/Onkologie; Berlin, Klinikum Neukölln, Abteilung Hämatologie/Onkologie; Frankfurt/Oder, Klinikum, Klinik für Innere Medizin; Frankfurt, Krankenhaus Nordwest, II. Medizinische Klinik; Lahr, Klinikum Lahr, Medizinische Klinik/Gastroenterologie; Sindelfingen, Städtisches Krankenhaus, Innere Medizin; Regensburg, Krankenhaus der Barmherzigen Brüder, Klinik für internistische Onkologie und Hämatologie; Wiesbaden, Dr. Horst-Schmidt-Kliniken, Innere Medizin III, Hämatologie/Onkologie; Stade, Klinik Dr. Hancken, Abteilung für Hämatologie; Trier, Krankenanstalt Mutterhaus der Borromäerinnen, Medizinische Klinik; Hildesheim, St. Bernward-Krankenhaus, Medizinische Klinik II; Halle, Martin-Luther-Universität Halle-Wittgenstein, Medizinische Klinik und Poliklinik IV; Kassel, Klinikum, Hämatologie/Onkologie; Rostock, Universität, Innere Medizin Onkologie/Hämatologie; Ravensburg, Oberschwabenklinik, Innere Abteilung; Duisburg, St. Johannes Hospital, Medizinische Klinik II; Hagen, Marienhospital, Hämatologische/Onkologische Station; Mönchengladbach, Kliniken Maria Hilf, Abteilung I; Jena, Dr. med. Hahnfeld, Hämatologische/Onkologische Gemeinschaftspraxis; Aurich, Kreis-Krankenhaus, Innere Medizin/Hämatologie; Hannover, Medizinische Hochschule, Abteilung Hämatologie/Onkologie; Hamburg, Gemeinschaftspraxis Prof. Dr. Kleeberg; Trier, Krankenhaus der Barmherzigen Brüder, I. Medizinische Abteilung; Bonn, Universitäts-Klinik, Medizinische Klinik und Poliklinik; Köln, Krankenhaus Merheim, Lungenklinik Onkologische Abteilung; Ludwigshafen, Klinikum der Stadt, Medizinische Klinik A; Duisburg, Johanniter-Krankenhaus Rheinhausen, Medizinische Klinik II/Onkologie; Stuttgart, Diakonissen-Krankenhaus, Innere Medizin II; Günzburg, Kreis-Krankenhaus, Innere Medizin; Pforzheim, Städtisches Krankenhaus, Medizinische Klinik II; Berlin, Vivantes, Hämatologie-Onkologische Beratung; Ulm, Universitäts-Klinik, Innere Abteilung III; München, Städtisches Krankenhaus Harlaching, IV. Medizinische Abteilung; Kaiserslautern, Westpfalz Klinikum, Innere med. I/Hämatologie; Lüdenscheid, Kreis-Krankenhaus, Innere Abteilung/Onkologie; Oldenburg, Dr. Otremba, Gemeinschaftspraxis Innere Medizin; Dresden, Krankenhaus Dresden-Friedrichstadt, I. Medizinische Klinik; Hamburg, Dr. Verpoort, Praxis Innere Medizin; Münster, Dr. KriebelSchmitt, Hämatologische/Onkologische Gemeinschaftspraxis; Gütersloh, Städtisches Krankenhaus, Medizinische Klinik/Hämatologie; Oldenburg, Städtische Kliniken, Innere Medizin II; Stuttgart, Katharinenhospital, Klinik für Onkologie; Waldbröl, Kreis-Krankenhaus, Medizinische Klinik; Limburg, St. Vincentius Krankenhaus, Abteilung Hämatologie; Freiburg, Evangelisches Diakonie-Krankenhaus, Innere Abteilung; Aalen, Kreis-Krankenhaus Ostalb-Klinikum, Innere Abteilung; Lebach, Caritas-Krankenhaus, Innere Medizin; Hameln, Krankenhaus des Kreises Hameln/Pyrmont, Innere Abteilung; Bonn, Medizinische Poliklinik, Innere Medizin; München, Klinikum Großhadern, Klinik III für Hämatologie/Onkologie; Neuss, Lukas-Krankenhaus, Medizinische Klinik II; Magdeburg, Städtisches Klinikum, Innere Medizin Abteilung Hämatologie/Onkologie; Leipzig, Universitäts-Klinik, Medizinische Abteilung Hämatologie/Onkologie; Hannover, Krankenhaus Siloah, Klinik für Hämatologie und Onkologie; Hamburg, Allg. Krankenhaus Barmbeck, Onkologische Abteilung; Freiburg, Klinik für Tumorbiologie, Klinik für Internistische Onkologie; Trier, Dr. Grundheber, Onkologische Schwerpunktpraxis; Greifswald, Ernst-Moritz-Arndt-Universität, Innere Medizin C Abteilung Hämatologie/Onkologie; Mülheim/Ruhr, Ev. Krankenhaus, Medizinische Klinik; Innsbruck, Austria, Universitäts-Klinikum, Institut für Epidemiologie; Worms, Dr. Burkhard, Onkologische Schwerpunktpraxis; Wuppertal, Bethesda Krankenhaus, Innere Abteilung; Herford, Klinikum Kreis, Medizinische Klinik II. 


\section{REFERENCES}

1. Connors JM, Klimo P, Adams G, et al. Treatment of advanced Hodgkin's disease with chemotherapy - comparison of MOPP/ $\mathrm{ABV}$ hybrid regimen with alternating course of MOPP and ABVD: a report from the $\mathrm{Na}$ tional Cancer Institute of Canada clinical trials group. J Clin Oncol 1997;15:1638-45. [Erratum, J Clin Oncol 1997;15:2762.]

2. Canellos GP, Anderson JR, Propert KJ, et al. Chemotherapy of advanced Hodgkin's disease with MOPP, ABVD, or MOPP alternating with ABVD. N Engl J Med 1992;327 1478-84.

3. Cullen MH, Stuart NSA, Woodroffe C, et al. ChlVPP/PAB1OE and radiotherapy in advanced stage Hodgkin's disease. J Clin Onco 1994;12:779-87.

4. Hancock BW, Vaughan Hudson G, Vaughan Hudson B, et al. LOPP alternating with EVAP is superior to LOPP alone in the initial treatment of advanced Hodgkin's disease: results of a British National Lymphoma Investigation trial. J Clin Oncol 1992;10 1252-8.

5. Longo DL, Duffey PL, DeVita VTJr, et al Treatment of advanced-stage Hodgkin's dis ease: alternating noncrossresistant MOPP CABS is not superior to MOPP. J Clin Onco 1991;9:1409-20.

6. Josting A, Franklin J, May M, et al. New prognostic score based on treatment outcome of patients with relapsed Hodgkin's lymphoma registered in the database of the German Hodgkin's Lymphoma Study Group. J Clin Oncol 2002;20:221-30.

7. Bonfante V, Santoro A, Viviani S, et al. Outcome of patients with Hodgkin's disease failing after primary MOPP-ABVD. J Clin Oncol 1997;15:528-34.

8. Frei E III, Canellos GP. Dose: a critical factor in cancer chemotherapy. Am J Med 1980;69:585-94

9. van Rijswijk REN, Haanen C, Dekker AW, de Meijer AJ, Verbeek J. Dose intensity of MOPP chemotherapy and survival in Hodgkin's disease. J Clin Oncol 1989;7 1776-82.

10. Hasenclever D, Loeffler M, Diehl V. Rationale for dose escalation of first line conventional chemotherapy in advanced Hodgkin's disease. Ann Oncol 1996;7:Suppl 4: 95-8.

11. Loeffler M, Hasenclever D, Diehl V. Model based development of the BEACOPP regimen for advanced stage Hodgkin's disease. Ann Oncol 1998;9:Suppl 5:S73-S78.

12. Diehl V, Sieber $M$, Rüffer $U$, et al BEACOPP: an intensified chemotherapy regimen in advanced Hodgkin's disease. Ann Oncol 1997;8:143-8.
13. Tesch H, Diehl V, Lathan B, et al. Moderate dose escalation for advanced stage Hodgkin's disease using the bleomycin, etoposide adriamycin, cyclophosphamide, vincristine, procarbazine and prednisone scheme and adjuvant radiotherapy: a study of the German Hodgkin's Lymphoma Study Group. Blood 1998;92:4560-7.

14. Diehl V, Franklin J, Hasenclever D, et al. BEACOPP, a new dose-escalated and accelerated regimen, is at least as effective as COPP/ABVD in patients with advanced-stage Hodgkin's lymphoma: interim report from a trial of the German Hodgkin's Lymphom Study Group. J Clin Oncol 1998;16:3810-21. 15. Diehl V, Franklin J, Paulus U, et al. BEACOPP chemotherapy improves survival, and dose escalation further improves tumour control in advanced stage Hodgkin's disease: GHSG HD9 results. Leuk Lymphoma 2001 42:Suppl 2:16-7. abstract.

16. Whitehead J. The design and analysis of sequential clinical trials. 2nd ed. Chichester, England: John Wiley, 1992.

17. Hasenclever D, Diehl V. A prognostic score for advanced Hodgkin's disease. N Engl J Med 1998;339:1506-14.

18. Engel C, Loeffler M, Schmitz S, Tesch $\mathrm{H}$ Diehl V. Acute hematologic toxicity and practicability of dose-intensified BEACOPP chemotherapy for advanced stage Hodg kin's disease. Ann Oncol 2000;11:1105-14 19. Carde P, Cavalli F, Diehl V, Franklin J. Is escalated BEACOPP a standard therapy for advanced Hodgkin's disease? Hematol 2000;1:282-90.

20. Horning SJ, Hoppe RT, Breslin S, Bar tlett NL, Brown BW, Rosenberg SA. Stanford $\mathrm{V}$ and radiotherapy for locally extensive and advanced Hodgkin's disease: mature results of a prospective clinical trial. J Clin Oncol 2002;20:630-7.

21. Raemaekers J, Burgers M, Henry-Ama $\mathrm{H}$, et al. Patients with stage III/IV Hodgkin' disease in partial remission after MOPP ABV chemotherapy have excellent prognosis after additional involved-field radiotherapy: interim results from the ongoing EORTC-LCG and GPMC phase III trial. Ann Oncol 1997;8:Suppl 1:111-4.

22. Radford JA, Rohatiner AZS, Ryder WDJ, et al. ChlVPP/EVA hybrid versus the weekly VAPEC-B regimen for previously untreated Hodgkin's disease. J Clin Oncol 2002;20 2988-94.

23. Valagussa P, Santoro A, Fossati-Bellan F, Banfi A, Bonadonna G. Second acute leukemia and other malignancies following treatment for Hodgkin's disease. J Clin Oncol 1986;4:830-7.
24. Duggan D, Petroni G, Johnson J, et al MOPP/ABV versus ABVD for advanced Hodgkin's disease - a preliminary report ofCALGB 8952 (with SWOG, ECOG, NCIC). Prog Proc Am Soc Clin Oncol 1997;16:12a. abstract.

25. Hess CF, Kortmann RD, Schmidberger $\mathrm{H}$, Bamberg M. How relevant is secondary leukaemia for initial treatment selection in Hodgkin's disease? Eur J Cancer 1994;30A: 1441-7.

26. van Leeuwen FE, Chorus AMJ, van den Belt-Dusebout AW, et al. Leukemia risk following Hodgkin's disease: relation to cumulative dose of alkylating agents, treatment with teniposide combinations, number of episodes of chemotherapy, and bone marrow damage. J Clin Oncol 1994;12:1063-73. 27. Micallef INM, Lillington DM, Apostolidis J, et al. Therapy-related myelodysplasia and secondary acute myelogenous leukemia after high-dose therapy with autologous hematopoietic progenitor-cell support for lymphoid malignancies. J Clin Oncol 2000; 18:947-55.

28. Kreuser ED, Felsenberg D, Behles C, et al. Long-term gonadal dysfunction and its impact on bone mineralization in patients following COPP/ABVD chemotherapy for Hodgkin's disease. Ann Oncol 1992;3: Suppl 4:105-10.

29. Brusamolino E, Lunghi F, Orlandi E, et al. Treatment of early-stage Hodgkin's disease with four cycles of ABVD followed by adjuvant radio-therapy: analysis of efficacy and long-term toxicity. Haematologica 2000 85:1032-9.

30. Khalifa E, Oehninger S, Acosta AA, et al. Successful fertilization and pregnancy outcome in in-vitro fertilization using cryopreserved/thawed spermatozoa from patients with malignant diseases. Hum Reprod 1992; 7:105-8.

31. Walshe R, Glossmann J-P, Waldschmidt $\mathrm{D}$, et al. Comparing costs and effectiveness of COPP/ABVD and BEACOPP escalated regimens for advanced stages of Hodgkin's disease. Leuk Lymphoma 2001;42:Suppl 2 106. abstract.

32. Loeffler M, Brosteanu $\mathrm{O}$, Hasenclever $\mathrm{D}$, et al. Meta-analysis of chemotherapy versus combined modality treatment trials in Hodg kin's disease. J Clin Oncol 1998;16:818-29. 33. Franklin J, Diehl V. Current clinical trials for the treatment of advanced-stage Hodgkin's disease: BEACOPP. Ann Oncol 2002; 13:Suppl 1:98-101.

Copyright (c) 2003 Massachusetts Medical Society. 